IZADP No. 2026

The Effect of Benefits on Single Motherhood in Europe

Libertad González

March 2006 


\title{
The Effect of Benefits on Single Motherhood in Europe
}

\author{
Libertad González \\ Universitat Pompeu Fabra \\ and IZA Bonn
}

Discussion Paper No. 2026

March 2006

\author{
IZA \\ P.O. Box 7240 \\ 53072 Bonn \\ Germany \\ Phone: +49-228-3894-0 \\ Fax: +49-228-3894-180 \\ Email: iza@iza.org
}

\begin{abstract}
Any opinions expressed here are those of the author(s) and not those of the institute. Research disseminated by IZA may include views on policy, but the institute itself takes no institutional policy positions.

The Institute for the Study of Labor (IZA) in Bonn is a local and virtual international research center and a place of communication between science, politics and business. IZA is an independent nonprofit company supported by Deutsche Post World Net. The center is associated with the University of Bonn and offers a stimulating research environment through its research networks, research support, and visitors and doctoral programs. IZA engages in (i) original and internationally competitive research in all fields of labor economics, (ii) development of policy concepts, and (iii) dissemination of research results and concepts to the interested public.
\end{abstract}

IZA Discussion Papers often represent preliminary work and are circulated to encourage discussion. Citation of such a paper should account for its provisional character. A revised version may be available directly from the author. 
IZA Discussion Paper No. 2026

March 2006

\section{ABSTRACT \\ The Effect of Benefits on Single Motherhood in Europe ${ }^{*}$}

This paper uses data from the eight waves of the European Community Household Panel (1994-2001) to estimate the impact of welfare benefits on the incidence of single motherhood and headship among young women across European countries. The regressions include country fixed effects as well as time trends that are allowed to vary by country, to account for fixed and trending unmeasured factors that could influence both benefit levels and family formation. The analysis also accounts for individual characteristics and labor market conditions. The results suggest that benefit levels have a small but significant positive effect on the prevalence of single mothers. An increase in yearly benefits of 1,000 euros is estimated to increase the incidence of single mother families by about 2 percent.

JEL Classification: J12, J13, I38

Keywords: $\quad$ single mothers, welfare benefits

Corresponding author:

Libertad González

Universitat Pompeu Fabra

Department of Economics and Business

Ramón Trias Fargas 25-27

08005 Barcelona

Spain

Email: libertad.gonzalez@upf.edu

\footnotetext{
* I thank the participants in the IZA Conference on Women and the Labor Market in Europe (Bonn, December 2004) for their comments. All remaining errors are mine.
} 


\section{Introduction}

Single mother households have become an increasingly frequent family type in many industrialized nations over the past few decades. This trend has been very pronounced in countries like the United States and the United Kingdom, attracting a great deal of attention from researchers and policy makers. ${ }^{1}$ The main concern is that single motherhood seems to be associated with poverty and negative outcomes for children. ${ }^{2}$

A large number of studies have looked into the impact of welfare benefits on partnership and fertility, mostly focusing on the US (Murray 1984, Ellwood and Bane 1985, Moffitt 1994, 1995, 1998, 2000, Hoynes 1997, Blau et al. 2004). Most studies exploit variation in benefits across states and over time to identify the effect of interest. Some include state fixed effects to account for unmeasured state-specific variables that may affect both benefit levels and single motherhood. These studies tend to find either no effects or small, marginally significant ones. Few studies have used European data to address this question. ${ }^{3}$

This paper contributes to the literature on the effect of benefits on the incidence of single mothers by exploiting the large cross-country variation in welfare benefits in Europe, which provides an excellent source of identification for the effect of interest. ${ }^{4}$ I use data from the European Community Household Panel (ECHP) for 14 countries over an eight-year period (1994 through 2001). This allows for the inclusion of country fixed effects in the regressions, accounting for unobserved factors at the country level that may be correlated both with benefit levels and the incidence of single motherhood.

\footnotetext{
${ }^{1}$ For recent research on the prevalence of single mothers in the US, see Blau et al. (2004), Neal (2004), Schmidt (2003), Moffitt (2000), Rosenzweig (1999), Hoynes (1997), Akerlof et al. (1996). See Del Bono (2004) for a recent study on pre-marital fertility in Britain. See Burdett and Ermisch (2002) and Willis (1999) for theoretical models of the formation of single mother families.

${ }^{2}$ Lerman (1996), McLanahan \& Sandefur (1994), Krein \& Beller (1988).

${ }^{3}$ Those who have done so have focused mostly on the UK. See for instance Del Bono (2004).

${ }^{4}$ Gonzalez (2005) uses Luxembourg Income Study Data for 14 countries to evaluate the effect of economic variables on single motherhood. However, the use of repeated cross-sections does not allow for the introduction of individual fixed-effects.
} 
Including country fixed effects might still yield biased estimates if there are unmeasured changes over time that are correlated with changes in welfare benefits. I account for this possibility by including time trends that are allowed to vary by countries or groups of countries. ${ }^{5}$ I also include individual-level controls such as age and education level, as well as aggregate measures of labor market conditions. The longitudinal nature of the data set also allows for the inclusion of individual fixed effects.

Separate regressions are estimated for single motherhood and single headship, in order to account for the possibility that the effect of benefits may take place through coresidence arrangements rather than fertility or partnership decisions. Benefit levels are estimated as the level of family-related allowances and social assistance received by a typical single mother household in a given country and year. I focus on young women (aged 18 to 35), whose family formation decisions are most likely to be affected by current labor market conditions and benefit levels.

The countries with higher benefit levels are also those where single mothers are more prevalent, which, of course, does not necessarily imply causality. Once we introduce the country fixed effects and the time effects, the estimated impact of benefits becomes smaller but remains positive and significant in many specifications. The results suggest that an increase in yearly benefits available to single mothers of 1,000 euros would increase the incidence of these households by about 2 percent.

The remainder of the paper is organized as follows. Section 2 briefly reviews the literature on the effects of welfare benefits on family formation. The following section provides an overview of social protection systems in Europe. Section 4 introduces the data and describes the methodology. Then section 5 discusses the main results and some additional specifications, and a final section concludes.

\footnotetext{
${ }^{5}$ A similar approach was implemented in Blau et al. (2004), who estimate the effect of benefits on single motherhood in the US including MSA fixed effects and MSA-specific time trends.
} 


\section{Previous Literature}

The incidence of single mothers is undoubtedly affected by social, cultural and religious factors. It is also undeniable, however, that there are economic variables with a potential to influence fertility, partnership and co-residence decisions, as economic theory has long emphasized. Empirical research on this issue has typically followed the seminal work of Becker (Becker 1960, 1973, 1974, 1981, Becker et al. 1977, Becker and Barro 1988) in assuming that fertility and marriage decisions are influenced by the expected costs and benefits of the different choices available to the individual. Central to this theory are the opportunity cost of women's time and the gains to specialization in marriage.

The sharp rise in the prevalence of single mothers in the US during the 1980's and 1990's generated a large literature, that hypothesized one of the following alternative explanations for this trend: 1. Welfare incentives (Murray 1984, Moffitt 1994, 1995, Hoynes 1997, Blau et al. 2004); 2. Increased economic opportunities for women (McLanahan 1994, Edlund 2000, Schmidt 2003); 3. Reduced supply of marriageable men (Wilson 1987), or a combination of those (Rosenzweig 1999, Schultz 1994, Willis 1999, Moffitt 2000, Neal 2004). None of these hypotheses alone is totally satisfactory, and no consensus has been reached on the subject to date.

Economic theory unambiguously predicts that a higher level of public assistance available to single mother households should be positively associated with the incidence of this type of household. Both the absolute level of benefits available to single mothers and their degree of targeting would affect the attractiveness (or the feasibility) of single motherhood. For instance, AFDC welfare benefits in the US were not available to women without children or to married women. It was also harder to qualify for a single 
mother living with other relatives. Thus welfare benefits were subsidizing single mothers who headed their own households.

Becker's theory also predicts important roles of male and female labor market conditions. Better labor market opportunities for women would enable them to support children on their own (Schmidt 2003, McLanahan 1994, Edlund 2000). However, the lack of economic opportunities may lower the perceived costs of out-of-wedlock childbearing, especially for very young women (Rich and Kim 2002, Duncan and Hoffman 1990). Wages could also show a negative correlation with the prevalence of single mothers if, as some have suggested, marriage is a normal good (Moffitt 2000, Oppenheimer 1994). Thus, the effects of better female labor markets on the incidence of single motherhood are theoretically ambiguous.

Another potentially relevant factor is the availability of suitable partners. In other words, sex ratios and the supply of men with stable earnings prospects have a potential to influence partnership decisions. Some evidence has been provided that the supply of men as well as their earnings and employment prospects affect female marriage behavior (Wilson 1987, Angrist 2000, Wallace 2000, Brien 1997). Willis (1999) develops a theoretical framework that implies that out-of-wedlock childbearing should be more prevalent when females are in excess supply, and when the gains to marriage are small because male incomes are low.

However, the fact that marriage market prospects affect marriage rates does not necessarily imply that they also affect single motherhood, as Neal (2004) points out. While better male labor markets and greater availability of marriageable men raise the likelihood that women will marry, the resulting increase in marriage also increases the incidence of children, and thus the size of the group at risk of becoming single mothers through separation or divorce (Blau et al. 2004). 
Many previous studies have attempted to estimate the effect of welfare benefits on fertility and marriage in the United States, with mixed results. These analyses usually model the probability of being a female head as a function of individual and state characteristics, including welfare benefits. Most studies estimate cross-sectional regressions, which rely on interstate variation in benefits to identify the welfare effect (Schultz 1994). Some use more than one period and introduce state fixed-effects in order to control for omitted state variables (Moffitt 1994), and Hoynes (1997) also adds individual fixed-effects. A recent paper by Blau et al. (2004) introduces MSA rather than state fixed effects as well as MSA-specific time trends. Some find small significant effects (Schultz 1994, Rosenzweig 1999, Blau 2004), while some find no effect at all (Moffitt 1994, Hoynes 1997).

While previous studies on the impact of welfare on single motherhood have focused on a single country (mostly the US), a multi-country analysis is especially attractive since the large international variation in public support and labor market conditions provides an excellent source of identification for the effects of interest. This paper uses the eight waves of the European Community Household Panel to examine the impact of public assistance on family formation by taking into account country fixed effects and country-specific time trends. The longitudinal nature of the data also allows for the introduction of individual fixed effects. Thus we are accounting for unmeasured variables at the country level that might be correlated with both the level of benefits and the prevalence of single mothers, such as a country's tolerance for these types of families. We are also incorporating the possibility that these unobserved variables are changing at different rates in different countries, rather than assuming that they are fixed over time. Finally, the individual fixed-effects enable us to correct for individual-level unobserved heterogeneity. 
The analysis also includes proxies for labor and marriage market conditions. The analysis focuses on young women (those aged 18 to 35), since including older age groups would bring in women who made their family formation decisions at varying times, hence possibly under very different labor and marriage market conditions.

\section{Welfare Benefits in Europe}

The 14 countries included in the analysis belong to very different welfare state traditions. In particular, the benefit system is quite dissimilar from the US model in some of the countries in the sample. This section provides an overview of the main features of social protection systems in Europe, as well as how they compare to the American system with respect to benefits available to single mothers.

The US system of social protection is highly targeted to low-income single mothers. The main cash assistance program used to be the AFDC (Aid to Families with Dependent Children), which became TANF (Temporary Assistance for Needy Families) after the 1996 reforms. Food Stamps and the Earned Income Tax Credit are other programs available to single mother families. Many changes took place during the 1980s and 1990s, among them the 1996 PRWORA. ${ }^{6}$ One of the main features of these reforms was the increase in work requirements.

The US literature on single mothers and benefits has mostly been concerned with the incentives created by targeted benefits. However, note that the absolute level of benefits available to single mothers can also generate incentives, even in the absence of (or in addition to) the degree of targeting. For instance, it is a common belief in Southern Europe that one can simply not make ends meet as a single mother, due to the practical unavailability of social assistance (targeted or otherwise).

\footnotetext{
6 “Personal Responsibility and Work Opportunity Reconciliation Act”.
} 
European countries differ largely in the generosity of their social protection systems, as well as in their degree of targeting. Following the classification proposed by EspingAndersen (1990) and followed by Bertola et al. (2000), the Anglo-Saxon countries (United Kingdom and Ireland, as well as the US) belong to the "liberal" cluster in social policy. The welfare model in these countries is based on means-tested and in-work benefits, providing social benefits only for those in greatest need. Social assistance schemes have a larger participation than in any other group. In 2001, average receipt of social assistance and family-related allowances in single mother households was about 6,000 euros in the UK and Ireland. ${ }^{7}$

The Nordic countries (Denmark and Finland), on the other hand, share a strong social-democratic tradition of universal welfare provision. They have high levels of social protection expenditures (around one third of GDP), and a high share of in-kind service provision. Social assistance plays a very residual role. The average single mother in these countries received about 5,000 euros in benefits in 2001 .

The Benelux countries (Belgium, Luxembourg and the Netherlands) lie in between the Nordic and the Central European model. The Central European countries (Austria, Germany and France) embrace an employment-based model, according to which social benefits are given only to those who have been on the labor market, although social assistance provides a basic safety net. The average level of benefits received by single mothers in the Central European countries was about 3,000 euros in 2001.

Finally, the social protection system in Southern European countries (Italy, Spain, Greece and Portugal) is less mature and more fragmented than the Central-European countries, with highly idiosyncratic arrangements. The welfare state is characterized by the implicit assumption that social responsibilities (and thus informal assistance) are to

\footnotetext{
${ }^{7}$ Own estimates with ECHP data.
} 
be solved within the family network. Social protection expenditures are low in these countries (around one fourth of GDP). The average single mother received less than 500 euros in benefits in the Southern countries in 2001.

\section{Data and Methodology}

The data set used in the analysis is the European Union Household Panel (waves 1 through 8), spanning from 1994 until 2001. ${ }^{8}$ This data set is the best available option for international comparisons in Europe, as the same survey was conducted in all 15 European Union countries. ${ }^{9}$ Its main shortcomings are the short time period covered, and the low sample sizes at the country level once we restrict the population of interest.

There are many issues involved in settling on a specific definition of "single mother". In particular, we need to specify an age limit for the mother as well as the children, as well as restrict the marital status of the head, and decide whether to include cohabitants as single, and whether to include single parents who are co-residing with other relatives, such as the grandparents of the children. I define a single mother as an unmarried woman aged 18 to 35 living with her dependent children younger than 18 and not cohabiting with a partner. However, sensitivity analyses are performed using alternative definitions, such as different age cuts for the mother.

This definition of single mothers includes those who are in co-residence with other relatives. We may also be interested in the incidence of single mothers who head their own households. Thus, the analysis will be performed for two separate dependent variables. "Single motherhood" is defined as above and incorporates all single mothers independently of their co-residence situation, i.e. including single mothers living with other relatives, such as the grandparents of the children. The second outcome variable,

\footnotetext{
${ }^{8}$ The data start in the second wave for Austria and the third for Finland.

${ }^{9}$ I exclude Sweden since it is the only country for which the data are not longitudinal.
} 
which we will refer to as "single headship", indicates a single mother who lives by herself with her dependent children. ${ }^{10}$ The number of single mothers in the pooled sample is 6,580 , out of which 4,250 are single heads.

The key explanatory variable of interest is the generosity of the benefit system in a given country and period. Benefits are defined as social assistance payments and/or family-related allowances, and therefore encompass both means-tested programs such as the AFDC and universal family allowances such as those common in the Nordic countries. ${ }^{11}$

The ECHP provides information on the level of social assistance and family-related allowances received by all households. ${ }^{12}$ The ideal measure would indicate the level of benefits available to a single mother household with a given set of characteristics in each country and year. With this goal in mind, the following regression is estimated separately by country for the sample of single heads aged 18 to 55 :

$$
B_{i c t}=\alpha_{c}+S_{i c t} \gamma_{c t}+\mu_{c t}+v_{i c t}
$$

Where $B$ is the level of benefits received by a single head, and the vector of characteristics $S$ includes dummies for the number of children and the number of hours worked by the mother (as well as age of the youngest child in alternative specifications). The coefficients are allowed to vary by year and the regressions include separate year effects $(\mu)$. The results are then used to impute predicted benefits for a "typical" single mother household (a mother with two children and working 20 hours a week), as follows:

\footnotetext{
${ }^{10}$ Blau et al. 2004 also estimate separate regressions for single mothers and single heads. However, their definition of single mothers, as in much of the previous research on this issue, could not exclude cohabiting mothers from the sample.

${ }^{11}$ Social assistance and family allowances represent the most important sources of public transfers for single mother households. In our sample (single mothers aged 18 to 35), the median ratio of benefits to all social transfers is .72, and a large fraction of single mothers (more than a third) do not receive any other source of public transfers.

${ }^{12}$ ECHP variables H133 and H137.
} 


$$
\hat{B}_{c t}=\hat{\alpha}_{c}+\bar{S} \hat{\gamma}_{c t}+\hat{\mu}_{c t}
$$

This is the main measure of benefits available to single mothers that will be used in the analysis.

We then exploit country-level differences in welfare policy as well as labor and marriage market conditions to estimate the impact of these factors on young women's propensity to become single mothers or single heads. The following logit model for the determinants of single motherhood (headship) for individual $i$, in country $c$, and year $t$ is estimated:

$$
P\left(Y_{i c t}=1\right)=\Lambda\left(X_{i c t} \beta+Z_{c t} \omega\right)
$$

Where $Y$ is a dummy that takes value 1 if a woman is a single mother (head), $\Lambda$ is the logistic cumulative distribution function, $X$ is a vector of individual characteristics, $Z$ is a vector of country-specific factors, and $\beta$ and $\omega$ are coefficient vectors.

The vector $X$ includes measured characteristics of a woman that are expected to affect her labor market prospects, her attractiveness as a partner, and her preferences regarding marriage and children. I include age, age squared and age cubed, and I also include two dummies for education level: ${ }^{13}$ one that indicates the equivalent of high school graduation, and one that indicates a university degree. ${ }^{14}$ I include women currently enrolled in school as well as not enrolled.

In the vector $Z$, I include the measure of the generosity of the benefit system in a given country and period, as defined above. Benefits are expressed in current euros, using the exchange rates provided by the ECHP.

Several alternative measures of benefits levels are also explored. The first uses age of the youngest child as an additional variable to predict the amount of benefits received

\footnotetext{
${ }^{13}$ The ECHP does not provide very rich information on education levels.

${ }^{14}$ I also include a dummy for women still at school or with missing data for education.
} 
by a family. I also explore using the median level of benefits received by all single mother families in a given country and year, as well as the $75^{\text {th }}$ percentile.

The specification also includes as country-level control variables the male unemployment rate, and the adult male (ages 25-54) median wage level, as overall indicators of labor market conditions. As noted by Blau et al. (2004), this variable would also improve the interpretation of the benefit variable, since hourly wages are likely to be closely associated with living costs. Moreover, adult (ages 25 to 54) wages and unemployment are less likely to be endogenous to the behavior of the young women in the sample (aged 18 to 35). Wages are expressed in current euros and computed as net monthly earnings divided by the number of hours worked. ${ }^{15}$

Equation 3 is estimated on a pooled sample for all 14 countries with data for the eight waves, including country dummies, and year dummies, which are allowed to vary by countries or groups of countries. The omitted wave is the first (1994), and the omitted country is Denmark. The sample size for the main specification is 172,437 . The number of country-year cells is 109 .

\section{Results}

\section{A. Descriptive Statistics}

Table 1 shows the proportion of women in the sample who are single mothers and single heads in different years. Overall, 3.8 percent of women aged 18 to 35 are single mothers in the 14 countries included in the sample, and 2.5 percent are single heads. We observe a slight decline in the incidence of single mothers and heads between 1994

\footnotetext{
${ }^{15}$ Number of hours worked a month are calculated as number of hours worked a week, times 4.345.
} 
and 2001. ${ }^{16}$ However, both the incidence and its evolution over time vary considerably across the 14 countries.

Figure 1 displays the proportion of women aged 18 to 35 who are single heads in 1994 and 2001 by country. There are four countries with very low incidence of single mothers: Italy, Greece, Portugal and Spain (less than 1 percent in 2001). At the other end, in the UK more than 8 percent of young women were single heads in 2001. Most countries experienced a decline in the proportion of young single heads. The decline was statistically significant (at the $95 \%$ confidence level) only in Denmark and Finland. $^{17}$

Table 2 shows the estimated level of benefits available to single heads aged 18 to 55 in 1994 and 2001 (resulting from estimating equation 1), by country. ${ }^{18}$ Note the high correlation between the level of benefits and the incidence of single mothers. Benefits are very low both in 1994 and in 2001 in Greece, Spain, Italy and Portugal, countries with very low prevalence of single mothers. The UK is both the country with highest incidence of single motherhood and one of the highest in terms of benefit levels in 2001.

The above-mentioned correlation is evident if we plot benefit levels against the incidence of single mothers for all countries and years. This can be seen in figure 2, together with a univariate linear regression line. The correlation (.34) is positive and significant, indicating that countries with higher benefit levels also have higher incidence of single mother households.

\footnotetext{
${ }^{16}$ The fall is not significant at the $90 \%$ confidence level for either single mothers or single heads.

${ }^{17}$ See Gonzalez (2004) for a more detailed analysis of the changes in the incidence of single motherhood across European countries.

${ }^{18}$ For comparison purposes, the Appendix shows estimated benefits available to two parent families (with two children and the mother working 20 hours a week). Note that predicted benefits are higher for single mothers in practically all countries and years (the exceptions being Greece and Spain in 2001).
} 
This raw correlation of course does not necessarily imply causality. Once we introduce the country fixed-effects, identification will come from changes in the prevalence of single mothers following changes in benefits within a country and over time. Germany and the UK experienced large increases in benefit levels between 1994 and 2001, while there was a substantial decline in France. For descriptive purposes, I calculate the change in benefits and in the incidence of single mothers from year to year by country. These differences are shown in figure 3 , together with the regression line. The correlation between changes in benefits and changes in the incidence of single mothers is still positive, but the significance level is much lower.

These correlations, however, are only descriptive, since we also want to account for changes in the composition of the population as well as for other factors that may be changing across countries and over time, such as labor market conditions.

Descriptive statistics for the variables included in the main specification can be found in table 3. Mean age is 27. Almost 24 percent of women in the sample have a university degree, while 41 percent have only a high school degree. Average male hourly wage is 6.7 euros, and the average male unemployment rate is 6.8 .

\section{B. Main Specification}

Table 4 shows the results of estimating equation 3, for the outcomes of single motherhood and single headship. The entries are the coefficients for the benefits variable, their standard errors, and the marginal effects. All standard errors are robust and clustered by country and year. The regressions also include controls for age, education, male wages and male unemployment rates. The table presents results for cross-sectional models, models with year dummies or a common time trend, and dummies for countries or groups of countries. 
In the cross-sectional models (panel a), once we control for individual characteristics and some proxies for labor and marriage market conditions, the benefit variable has positive and significant coefficients both for single motherhood and headship, indicating that, before taking into account country fixed effects or time trends, higher benefits are associated with higher prevalence of single mothers and heads. These coefficients can be interpreted as long-term effects. The results suggest that a country with yearly benefits 1,000 euros above the mean has about $17 \%$ more single mothers than a country with an average level of benefits, while the incidence of single heads is about $15 \%$ higher. ${ }^{19}$

Introducing year dummies or a time trend (panels $\mathrm{b}$ and $\mathrm{c}$ ) barely alters the results, with a marginal effect of .006 for single motherhood and .003 for single headship. However, we may still worry that countries differ in unobserved dimensions that affect both the generosity of the welfare system and family formation decisions. We can address this concern by introducing dummies for groups of countries that share social norms and welfare regimes. A natural grouping is suggested by the welfare state regimes classification spelled out in section $3 .^{20}$ Introducing the group dummies (panels $\mathrm{d}$ and e) reduces the size of the effects considerably (marginal effect of .002 for single motherhood and .0006 for single headship). An additional set of specifications includes country-specific dummies (panels $\mathrm{f}$ and $\mathrm{g}$ ), which further reduces the size of the coefficients.

Even when we introduce the country and time effects, benefits remain significant in some of the specifications, although the estimated effects are smaller than suggested by

\footnotetext{
${ }^{19}$ The magnitudes are calculated by dividing the marginal effect by the average prevalence of single mothers (heads). For instance, $.0063 / .038=.17$. Note that average benefits are 2,640 a year. Note also that five countries experienced an increase in benefits of more than 2,000 euros between 1994 and 2001 (see table 2).

${ }^{20}$ The liberal or Anglosaxon model (UK and Ireland); the Continental model (Germany, The Netherlands, France, Austria, Belgium, Luxembourg); the social-democratic or Nordic model (Finland, Denmark), and the familistic or Southern model (Spain, Portugal, Italy, Greece).
} 
the cross-sectional correlations. Most of the country dummies are also significant, while the year dummies (common for all countries) are not. The results indicate that a 1,000 euros increase in yearly benefits is associated with a $1 \%$ increase in single motherhood and a 1 to $2 \%$ increase in single headship. Thus, it seems that benefit levels may have an effect on both co-residence arrangements and fertility or partnership decisions.

Table 5 shows the coefficients for the rest of the explanatory variables in selected specifications. As reported in previous studies, older, less educated women are significantly more likely to become single mothers. Note that education has a stronger effect on single motherhood than on household headship. Male unemployment rates show a negative and significant coefficient in the specification for single heads with country fixed-effects. Male wages do not appear to have a significant effect. The interpretation of the coefficients on male wages and unemployment is however not straightforward since they are capturing both labor market and marriage market effects.

Even a specification with country dummies does not account for unmeasured factors such as changing norms and other time-varying forces that may cause changes in both benefits and the incidence of single motherhood at different paces in different countries or groups of countries. The use of the eight waves of the ECHP enables us to account for these factors by including year dummies or trends that vary by groups of countries. Table 6 shows the results from regressions where the year dummies or trends are specific to a country or group of countries.

The estimated effects remain significant when we interact the time effects with the groups of countries (panels a and b). These specifications account for time varying factors that may differ across groups of countries, as well as fixed group effects. According to these specifications, on average, 1,000 more euros in yearly benefits is associated with an incidence of single mothers about .3 percentage points higher, for an 
average prevalence of 3.8 percent of women. This implies an $8 \%$ increase in the number of single mothers, while the effect on single headship would be a $3.5 \%$ increase.

Panels $\mathrm{c}$ and $\mathrm{d}$ show the results from specifications with country dummies in addition to the interaction between year and group of countries. Thus we are accounting for unmeasured variables at the country level, as well as changes over time that are allowed to vary by groups of countries. In these specifications, benefits are not significant in explaining the prevalence of single mothers, but they do appear to have a significant effect on single household headship (panel c). The magnitude of the effect is such that an increase in benefits of 1,000 euros would be associated with a $1.5 \%$ increase in the incidence of single mothers heading their own household. This suggests that benefit levels may have a more significant effect on co-residence arrangements than on fertility or partnership decisions. ${ }^{21}$

Finally, panel e allows for country-specific time trends in addition to the country dummies, i.e., we are accounting for unobserved, time-varying factors at the country level. Once we do this, benefits become insignificant and the signs turn negative. This suggests that the positive effect found in previous specifications may be spurious and could be attributed to changing country-specific factors that are related to both benefit levels and the incidence of single mothers. For instance, social norms may be changing at different paces across countries, and influencing both family formation decisions and public policy.

However, note that the identification strategy relies on difference in benefits across 109 country-year cells, and we are including thirteen country dummies plus seven year dummies and fourteen separate time trends, with at most eight years of data per country.

\footnotetext{
${ }^{21}$ Or, as a referee noted, it could also be that single mothers who live alone with their children ("single heads") are a different group with higher responses to policies.
} 
Thus there is very little variation left to be picked up by the benefits variable in the final specification.

\section{Additional Specifications and Robustness Checks}

The reported results are robust to a variety of alternative specifications. The regressions are run with several different age cuts for women, with similar results. Alternative definitions are explored for the benefits variable. In particular, adding age of the youngest child to estimate benefit levels (in equation 1) barely alters the coefficients. Mean benefits and $75^{\text {th }}$ percentiles are also employed instead of predicted benefits, with slightly different significance levels and magnitudes of the coefficients as a result, but the main conclusions remain unchanged. The same can be said of specifications that include all social transfers in the definition of benefits. ${ }^{22}$

Low-educated women are more likely to be affected by changes in benefit levels than more educated young women. Thus regressions are estimated excluding women with a university education, and excluding also those with a high school degree. Results from representative specifications are reported in table 7 . Benefits remain significant in most specifications and insignificant in the one with country dummies and countryspecific trends. As expected, the magnitude of the effects is higher.

Economic theory as well as common sense suggest that the incentives faced by women at risk of becoming single mothers may be quite different for never married women who decide to have a child on their own, versus married women with children and considering divorce. Thus I estimate the regressions separately for the sample of never married women and ever-married women with children. These results are reported in table 8. Benefits are significant determinants of single motherhood for both samples, although significance levels are higher in the specifications for ever-married women.

\footnotetext{
${ }^{22}$ Regression results with the alternative definitions of the benefits variable are available upon request.
} 
In the specifications with time trends (but no group or country dummies), the coefficients on benefits are positive and significant for both never married and divorce motherhood (panel a). They remain significant when we include the dummies for groups of countries (panel b). However, adding country dummies turns the coefficient for benefits insignificant in the regressions for never married mothers (panel c). Benefits remain significant in the specifications for ever-married mothers even when we include trends that vary by groups of countries (panel e). According to this specification, a 1,000 euros increase in benefits would lead to a $10 \%$ increase in the incidence of divorced mothers (as a proportion of all ever-married women with children), and a 16\% increase in the number of divorced married mothers heading their own households. However, once we allow the trends to be country-specific (panel f), benefits are no longer significant as determinants of either group of single mothers.

\section{Individual Fixed Effects}

Hoynes (1997) noted that, in a panel data source, if the composition of state (or, in our case, country) populations changes over time through migration of individuals and sample attrition or entry, the state (country) fixed-effects specification may still yield spurious results, which could be avoided with the inclusion of individual fixed effects. Since the ECHP is a longitudinal database, this concern led us to explore specifications with individual fixed effects. Note that, if no one moved and no one left or entered the panel after the first wave, then country fixed effects and individual fixed effects would provide the same information.

In the specifications with individual fixed-effects, identification comes only from women whose status in terms of the outcome variable changed during the period, thus 
the number of observations substantially drops, ${ }^{23}$ which is potentially a problem given the already low number of observations in some of the countries. Also, controls that do not vary over time for a given individual (such as the country dummies) need to be dropped. Table 9 shows the results of the fixed effects specifications for the sample of women aged 18 to 35 and the expanded sample of women 18 to 45 . Including older women may be more appropriate in the fixed-effect specifications since we are focusing on women who either become a single mother or transition out of this state during the period of observation, thus at least some family formation or dissolution decisions are being taken at the time the survey is conducted.

The estimated effect of benefits is positive in most specifications but is essentially never significant in neither the specifications for single mothers or single heads with individual fixed effects. This is true even in the specifications without country or group specific trends.

Alternative fixed effects specifications are estimated including only women with low schooling, and separating never married and ever married women, for different age cuts. The conclusion remains that, once we include individual fixed effects, benefits are not significantly associated with a higher incidence of single mothers or single heads.

This suggests that the positive association found in regressions without individual fixed effects may be attributable to unobserved, individual-specific heterogeneity. Note that part of the effect of the changing sample of women within country (due to sample attrition and entry) was captured by the country-specific trends in the specifications without the individual fixed effects.

However, there are reasons to think that the fixed effect specifications may not be the preferred ones in the current setting. First, as mentioned, the severe drop in the

\footnotetext{
${ }^{23}$ From 172,437 to 8,755 (in the regressions for single motherhood) and 6,476 (in the regressions for single headship).
} 
number of observations leads to a decline in significance levels. Second, migration rates across countries in Europe are lower than across US states, thus one of the main justifications for the use of fixed effects appears to be less important in this application. Together with the short length of the panel, these considerations suggest that the fixed effects results should be taken with a grain of salt.

\section{Conclusions}

This paper estimates the effect of benefits on the incidence of single motherhood in Europe. Using ECHP data from 1994 through 2001, regressions are estimated where the likelihood of a young woman being a single mother is assumed to depend on her personal characteristics, labor and marriage market conditions, and public support, as well as country fixed effects and time trends that are allowed to vary by country or groups of countries. Controlling for country fixed effects and trends is important since country-specific factors such as norms or other unmeasured social or economic factors and their evolution over time may affect both the provision of benefits and individual family-formation decisions.

A simple cross-section shows that the countries where single mothers are more prevalent also provide higher benefit levels. This association may reflect long-term effects, but it can also be the result of unmeasured factors that affect both single parenthood and benefits. Once we control for individual characteristics and some proxies for labor and marriage market conditions, and we introduce country fixedeffects, the estimated effect is smaller than suggested by the cross-sectional correlations, but it remains positive and significant.

Even a specification with country dummies does not account for unmeasured factors at the country level, such as changing norms and other time-varying forces, which may 
cause changes in both benefits and the incidence of single motherhood. The use of the eight waves of the ECHP enables us to account for these factors by including time trends that are allowed to vary by groups of countries. Even in these specifications, benefits remain positive and significant, suggesting that an increase in family allowances or social assistance to single mother families of 1,000 euros a year would result in a 2 percent increase in the likelihood of a young woman being a single mother. The effect takes place both through increases in out-of-wedlock childbearing and divorce, and is stronger for low-educated single mothers.

The longitudinal nature of the ECHP allows us to also run specifications with individual fixed effects. These would yield more information than the specifications with country fixed effects if there was significant attrition or entry in the sample. Once we introduce the individual effects, benefits are no longer significantly positive in the specifications for either single mothers or single heads. Benefits are also insignificant in specifications without person fixed effects, but with time trends that are allowed to vary by individual countries. Thus the observed correlation between benefit levels and single motherhood across European countries may be attributable to unobserved heterogeneity, rather than a causal effect.

These results should be interpreted with some caution, due to several remaining caveats. First, the fixed effects specifications are placing a lot of weight on a relatively small number of observations. Second, it would be desirable to include more detailed measures of labor demand and supply in the regressions, for both men and women and, if possible, stratified by education level. Separate controls for marriage market conditions would also be desirable. Thirdly, the data set covers only an eight-year period, and the average number of periods per woman in the sample is six, thus we do not capture long-term trends in benefits or the incidence of single mothers. Moreover, 
several of the countries do not experience significant changes in the level of benefits between 1994 and 2001. The reduced-form specification also limits the interpretation of the results. For instance, we cannot separate the effects of the overall generosity of the welfare system from the degree of targeting. Finally, a more refined measure of benefit levels would reflect the national benefit schedules directly, rather than through benefits actually received by single mother households. 


\section{References}

Akerlof, G. A., J. L. Yellen and M. L. Katz. 1996. "An Analysis of Out-Of-Wedlock Childbearing in the United States." Quarterly Journal of Economics 111(2): 277-317.

Angrist, J. 2002. "How Do Sex Ratios Affect Marriage and Labor Markets? Evidence from America's Second Generation." Quarterly Journal of Economics 117(3): 997-1038.

Becker, G. S. 1960. "An Economic Analysis of Fertility." In Demographic and Economic Change in Developed Countries. Princeton, NJ: Princeton University Press.

Becker, G. S. 1973. "A Theory of Marriage: Part I." Journal of Political Economy 81(4): 813-846.

Becker, G. S. 1974. "A Theory of Marriage: Part II." Journal of Political Economy 82(2): S11-S26.

Becker, G. S. 1981. A treatise on the Family. Cambridge, Mass.: Harvard University Press.

Becker, G. S. and R. J. Barro. 1988. "A Reformulation of the Economic Theory of Fertility." Quarterly Journal of Economics 103(1): 1-25.

Becker, G. S., E. M. Landes and Robert T. Michael. 1977. "An Economic Analysis of Marital Instability." Journal of Political Economy 85(6): 1141-1188.

Bertola, G., F. Jimeno, R. Marimon and C. Pissarides. 2000. "Welfare Systems and Labour Markets in Europe: What Convergence Before and After EMU?" In Welfare and Employment in a United Europe ed. G. Bertola, T. Boeri and G. Nicoletti. Cambridge, MA: MIT Press.

Blau, F., L. Kahn and J. Waldfogel. 2004. "The Impact of Welfare Benefits on Single Motherhood and Headship of Young Women. Evidence from the Census." Journal of Human Resources 39(2): 382-404.

Brien, M. 1997. "Racial Differences in Marriage and the Role of Marriage Markets." Journal of Human Resources 32: 741-778.

Burdett, K. and J. F. Ermisch. 2002. "Single Mothers." Institute for Social and Economic Research Working Paper 30-2002. University of Essex.

Del Bono, Emilia. 2004. "Pre-Marital Fertility and Labour Market Opportunities: Evidence from the 1970 British Cohort Study.” IZA Discussion Paper No. 1320.

Duncan, G. and S. Hoffman. 1990. "Welfare Benefits, Economic Opportunities and the Incidence of Out-of-Wedlock Births Among Black Teenage Girls." Demography 27(4): 519-535. 
Edlund, L. 2005. "The Role of Paternity Presumption and Custodial Rights for Understanding Marriage Patterns.” Unpublished draft. Columbia University.

Ellwood, D. and M. J. Bane. 1985. "The Impact of AFDC on Family Structure and Living Arrangements." Research in Labor Economics 7: 137-207.

Esping-Andersen, G. 1990. The Three Worlds of Welfare Capitalism. Princeton University Press.

González, Libertad. 2005. "The Determinants of the Prevalence of Single Mothers: A Cross-Country Analysis.” IZA Discussion Paper No. 1677.

González, Libertad. 2004. "Single Mothers in Europe: A Decomposition Approach." Unpublished draft. Universitat Pompeu Fabra.

Hoffman, S. and G. Duncan. 1988. "A Comparison of Choice-Based Multinomial and Nested Logit Models: The Familiy Structure and Welfare Use Decisions of Divorced or Separated Women." Journal of Human Resources 23: 550-562.

Hoynes, H. W. 1997. "Does Welfare Play Any Role in Female Headship Decisions?", Journal of Public Economics 65: 89-118.

Krein, S. F. and A. H. Beller. 1988. "Educational Attainment of Children From SingleParent Families: Differences by Exposure, Gender, and Race." Demography 25(2): 221-234.

Lerman, R. 1996. "The Impact of the Changing US Family Structure on Child Poverty and Income Inequality" Economica 63(250): S119-39.

McLanahan, S. 1994. "The Consequences of Single Motherhood", American Prospect 18: 48-58.

McLanahan, S. and G. Sandefur. 1994. Growing up with a single parent: what hurts, what helps. Cambridge, Mass.: Harvard University Press.

Moffitt, R. 1994. "Welfare Effects on Female Headship with Area Effects." Journal of Human Resources 29: 621-636.

Moffitt, R. 1995. "The Effect of the Welfare System on Nonmarital Childbearing." In Report to Congress on Out-of Wedlock Childbearing. National Center for Health Statistics 95-1257-1. Hyattsville, Md.: Public Health Service.

Moffitt, R. 1998. "The Effect of Welfare on Marriage and Fertility." In Welfare, the Family, and Reproductive Behavior, ed. R. Moffitt. Washington: National Academy Press.

Moffitt, R. 2000 "Welfare Benefits and Female Headship in U.S. Time Series". American Economic Review 90(2): 373-377. 
Murray, C. 1984. Losing Ground - American Social Policy, 1950-1980. New York: Basic Books.

Neal, D. 2004. "The Relationship Between Marriage Market Prospects and NeverMarried Motherhood." Journal of Human Resources 39(4): 938-957.

Oppenheimer, V. K. 1994. "Women's Rising Employment and the Future of the Family in Industrial Societies." Population and Development Review 20: 293-342.

Rich, L. M. and S. Kim. 2002. "Employment and the Sexual and Reproductive Behavior of Female Adolescents." Perspectives on Sexual and Reproductive Health 34(3): 127-134.

Rosenzweig, M. R. 1999. "Welfare, Marital Prospects, and Nonmarital Childbearing." The Journal of Political Economy 107(6): S3-S32.

Schmidt, L. 2003. "Murphy Brown Revisited: Human Capital, Search and Nonmarital Childbearing Among Educated Women." Unpublished draft. Williams College.

Schultz, P. T. 1994. "Marital Status and Fertility in the United States. Welfare and Labor Market Effects." The Journal of Human Resources 29: 637-669.

Wallace, G. 2000. "An Assessment of Several Explanations for the Decline in Marriage." Unpublished draft. University of Wisconsin.

Willis, R. J. 1999. "A Theory of Out-Of-Wedlock Childbearing." Journal of Political Economy 107(6): S33-S64.

Wilson, W. J. 1987. The Truly Disadvantaged. Chicago: University of Chicago Press. 
Figure 1. Proportion of Women Aged 18 to 35 Who Are Single Heads

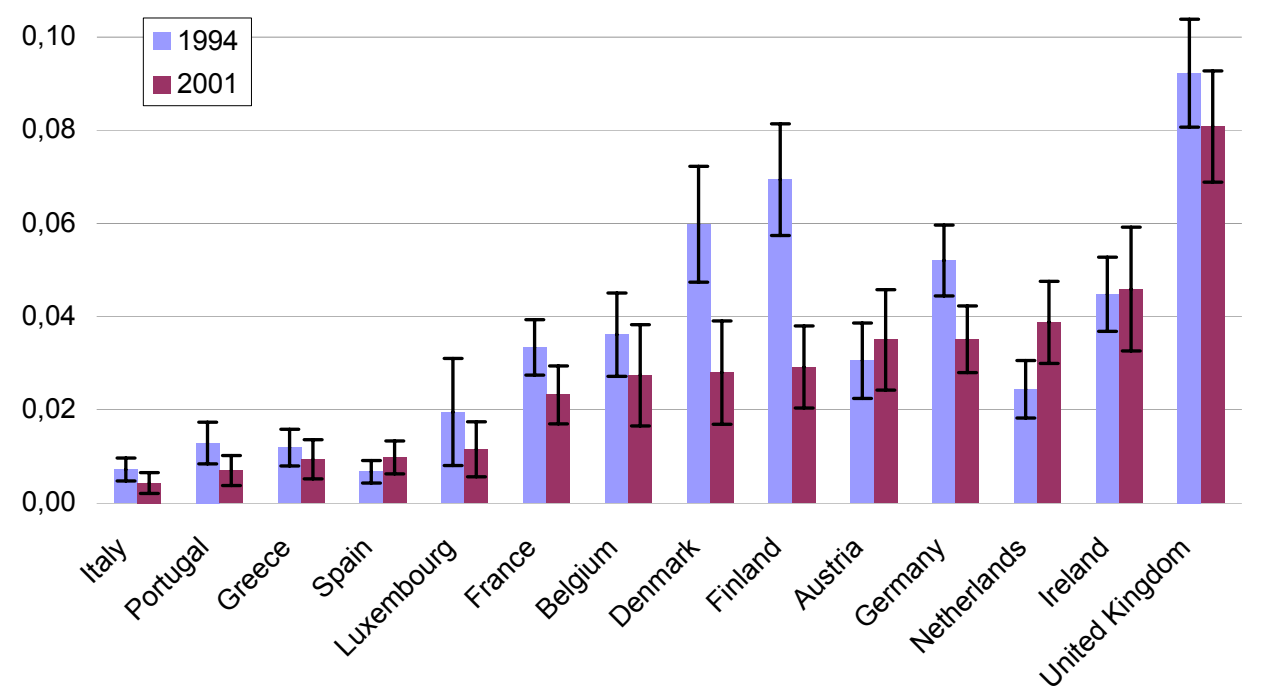

Note: ECHP data, waves 1 and 8, except for Finland (waves 3 and 8) and Austria (waves 2 and 8). Person weights have been used. Single heads are defined as unmarried women aged 18 to 35 who live on their own with their children, at least one of them younger than 18 . The error bars show \pm 1.645 the standard deviation of the proportions. 
Figure 2. Benefit Levels and Incidence of Single Mothers, 1994-2001

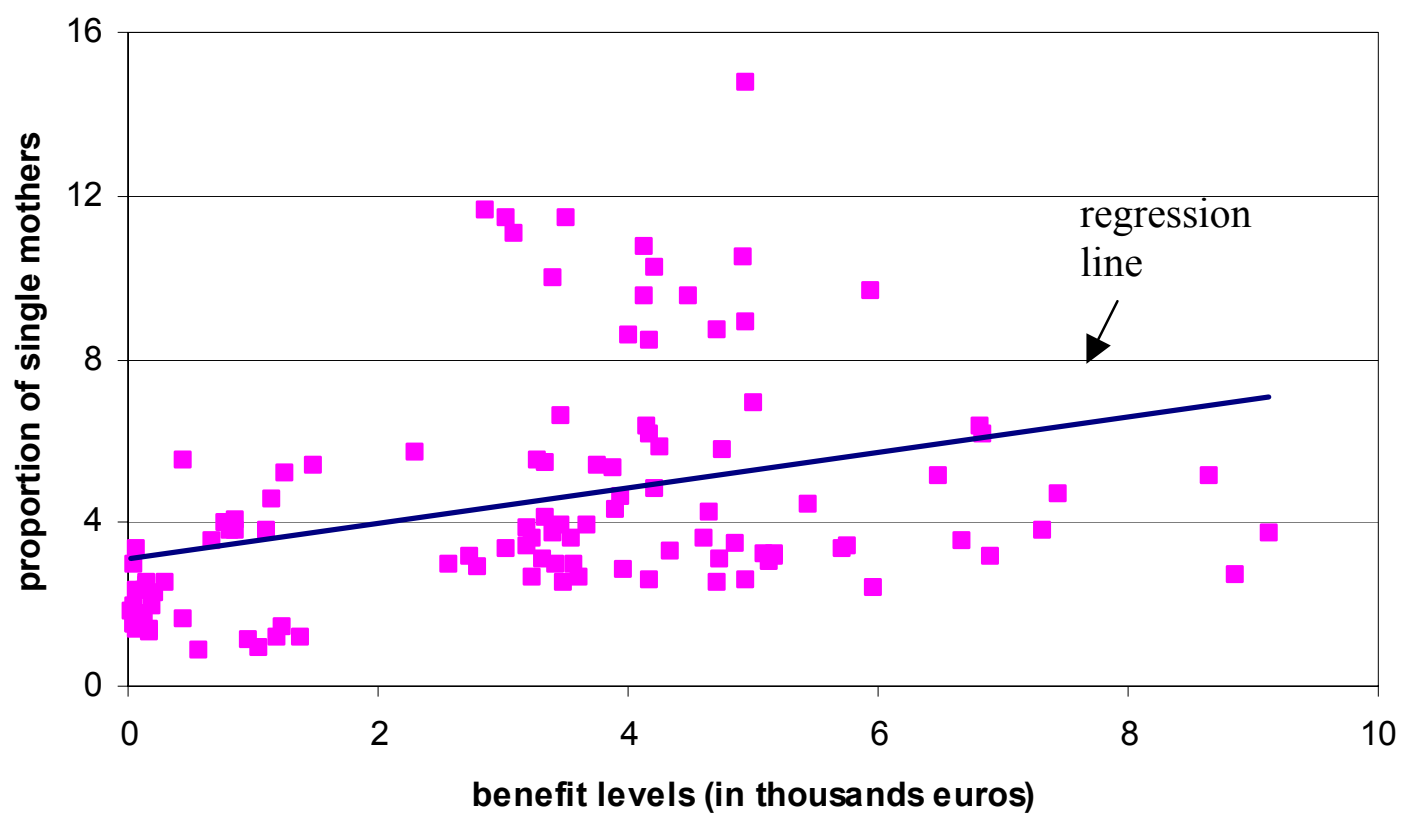

Note: ECHP data, waves 1 through 8, except for Finland (waves 3 and 8) and Austria (waves 2 and 8 ). Person weights have been used. Single mothers are defined as unmarried women aged 18 to 35 who live with their children younger than 18 and without a partner. "Benefit levels" are defined as predicted level of benefits (social assistance plus family allowances) available to single mothers. "Proportion of single mothers" is the proportion of women aged 18 to 35 who are single mothers. A point represents a country-year combination. The number of data points is 109. 
Figure 3. Changes in Benefits and in the Incidence of Single Mothers, 1994-2001

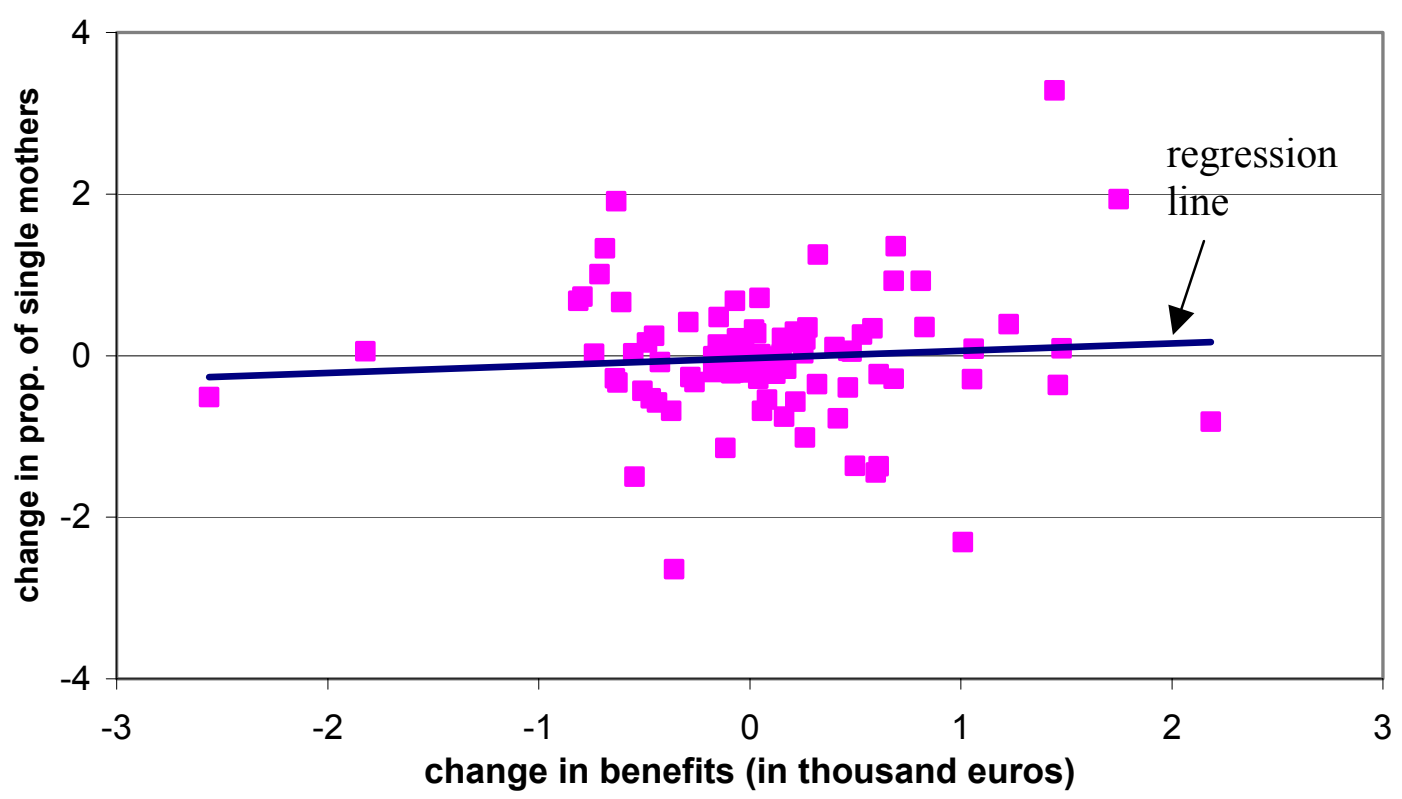

Note: ECHP data, waves 1 through 8, except for Finland (waves 3 and 8) and Austria (waves 2 and 8). Person weights have been used. Single mothers are defined as unmarried women aged 18 to 35 who live with their children younger than 18 and without a partner. "Change in benefit levels" are defined as the change in the predicted level of benefits available to single mothers from year to year. "Change in proportion of single mothers" is the year-to-year change in the proportion of women aged 18 to 35 who are single mothers. A point represents a country-year combination. The number of data points is 95 . 
Table 1. Proportion of Women 18-35 Who Are Single Mothers

\begin{tabular}{|c|c|c|}
\hline & Single mothers & Single heads \\
\hline 1994 & 0.0385 & 0.0258 \\
\hline 1997 & 0.0383 & 0.0241 \\
\hline 2001 & 0.0357 & 0.0225 \\
\hline $\begin{array}{c}\text { All } \\
\text { Waves }\end{array}$ & 0.0380 & 0.0246 \\
\hline $\mathrm{N}$ & 172,437 & 172,437 \\
\hline
\end{tabular}

Note: ECHP data for 14 countries (all but Sweden), waves 1 through 8. Unweighted means are shown. Single mothers are defined as unmarried women aged 18 to 35 who live with their children, at least one of them younger than 18, and without a partner (but maybe with other relatives). Single heads are defined as single mothers who live on their own with their children. 
Table 2. Predicted Benefits Single Heads in 1994 and 2001

\begin{tabular}{|l|c|c|c|}
\hline & $\mathbf{1 9 9 4}$ & $\mathbf{2 0 0 1}$ & $\mathbf{N}$ \\
\hline Austria & 3869 & 4163 & 641 \\
\hline Belgium & 3193 & 3415 & 847 \\
\hline Denmark & 6837 & 8860 & 753 \\
\hline Finland & 2840 & 5176 & 608 \\
\hline France & 3331 & 2784 & 431 \\
\hline Germany & 1245 & 4204 & 1434 \\
\hline Greece & 49 & 13 & 699 \\
\hline Ireland & 3388 & 4941 & 1615 \\
\hline Italy & 445 & 1047 & 1834 \\
\hline Luxembourg & 3470 & 5966 & 664 \\
\hline Netherlands & 4714 & 5753 & 994 \\
\hline Portugal & 661 & 441 & 386 \\
\hline Spain & 204 & 70 & 592 \\
\hline $\begin{array}{l}\text { United } \\
\text { Kingdom }\end{array}$ & 3014 & 5932 & 619 \\
\hline
\end{tabular}

Note: ECHP data (excluding Sweden). The table shows predicted values from benefit regressions at the country level with explanatory variables number of children, hours worked by the mother, and year. Waves 1 through 8, except for Finland (waves 3 through 8) and Austria (waves 2 through 8). Single heads are defined as unmarried women who live on their own with their children, at least one of them younger than 18. Benefit levels are expressed in euros and include family-related allowances and social assistance (ECHP variables H133 and H137). Predicted benefits are calculated for the sample of single heads aged 18 to 54 . The number of observations is shown in the last column. 
Table 3. Descriptive Statistics

\begin{tabular}{lcccc}
\hline Variable & Mean & Std. Dev. & Min & Max \\
\hline Single heads & 0,0246 & 0,1548 & 0 & 1 \\
Single mothers & 0,0380 & 0,1913 & 0 & 1 \\
Age & 26,65 & 5,176 & 18 & 35 \\
High school & 0,4098 & 0,4918 & 0 & 1 \\
University & 0,2389 & 0,4264 & 0 & 1 \\
Male unemp. & 6,808 & 3,304 & 1,1 & 16,4 \\
Male wage & 6,726 & 2,318 & 2,19 & 13,89 \\
Benefits & 2640 & 2109 & 13 & 9134 \\
\hline
\end{tabular}

Note: ECHP data (excluding Sweden), waves 1 through 8, except for Finland (waves 3 through 8 ) and Austria (waves 2 through 8). Sample size is 172,437. Benefit levels and male wages are expressed in euros. 
Table 4. Coefficients for the Effect of Benefits on Single Motherhood and Headship.

\begin{tabular}{|c|c|c|c|c|}
\hline & Single mother & & Single head & \\
\hline \multirow[t]{3}{*}{ a) Cross Section } & 0,2233 & $* * *$ & 0,2551 & $* * *$ \\
\hline & $(0,0323)$ & & $(0,0401)$ & \\
\hline & {$[0,00630]$} & & {$[0,00358]$} & \\
\hline \multirow[t]{3}{*}{ b) Year trend } & 0,2209 & $* * *$ & 0,2449 & $* * *$ \\
\hline & $(0,0332)$ & & $(0,0405)$ & \\
\hline & {$[0,00624]$} & & {$[0,00342]$} & \\
\hline \multirow[t]{3}{*}{ c) Year dummies } & 0,2266 & $* * *$ & 0,2503 & $* * *$ \\
\hline & $(0,0324)$ & & $(0,0405)$ & \\
\hline & {$[0,00639]$} & & {$[0,00349]$} & \\
\hline \multirow[t]{3}{*}{$\begin{array}{l}\text { d) Country (grouped) dummies and year } \\
\text { trend }\end{array}$} & 0,0785 & * & 0,046 & \\
\hline & $(0,0402)$ & & $(0,0366)$ & \\
\hline & {$[0,00211]$} & & {$[0,00055]$} & \\
\hline \multirow[t]{3}{*}{ e) Country (grouped) and year dummies. } & 0,0834 & ** & 0,0509 & \\
\hline & $(0,0395)$ & & $(0,0365)$ & \\
\hline & {$[0,00224]$} & & {$[0,00061]$} & \\
\hline \multirow[t]{3}{*}{ f) Country dummies and year trend } & 0,00996 & & 0,0242 & \\
\hline & $(0,0224)$ & & $(0,0205)$ & \\
\hline & {$[0,00025]$} & & {$[0,00028]$} & \\
\hline \multirow[t]{3}{*}{ g) Country and year dummies } & 0,0133 & & 0,0346 & * \\
\hline & $(0,0216)$ & & $(0,0205)$ & \\
\hline & {$[0,00034]$} & & {$[0,00039]$} & \\
\hline
\end{tabular}

Note: The coefficients are from logit regressions using ECHP data for 14 countries in eight waves (1994 through 2001). Robust standard errors are shown in parenthesis (clustered by country and year in all specifications). Marginal effects are in brackets. The sample includes all women aged 18 to 35 . The number of observations is 172,437 . Other variables included in the regressions are age, age squared, age cubed, two education dummies, male unemployment rates and median male wages. Two asterisks indicate that a variable is significant at the $95 \%$ level, and three indicate significance at the $99 \%$ level. Benefits are defined as predicted family-related allowances and social assistance received by a typical single head in a given country and period, and are measured in thousands of euros. The dummies for groups of countries (panels d, e) include one for the UK and Ireland, one for Spain, Italy, Greece and Portugal, and one for Finland and Denmark. 
Table 5. Selected Results for Control Variables

\begin{tabular}{|c|c|c|c|c|c|c|c|c|}
\hline & & gle m & other & & & ngle & head & \\
\hline \multirow[t]{3}{*}{ Age } & 2,312 & $* * *$ & 2,3072 & $* * *$ & 3,3118 & $* * *$ & 3,4634 & $* * *$ \\
\hline & $(0,3376)$ & & $(0,3301)$ & & $(0,4167)$ & & $(0,4195)$ & \\
\hline & {$[0,0653]$} & & {$[0,0584]$} & & {$[0,0462]$} & & {$[0,0395]$} & \\
\hline \multirow[t]{3}{*}{ Age squared } & $-0,076$ & $* * *$ & $-0,0754$ & $* * *$ & $-0,1066$ & $* * *$ & $-0,1117$ & $* * *$ \\
\hline & $(0,0128)$ & & $(0,0125)$ & & $(0,0155)$ & & $(0,0156)$ & \\
\hline & {$[-0,0021]$} & & {$[-0,0019]$} & & {$[-0,0015]$} & & {$[-0,0013]$} & \\
\hline \multirow{3}{*}{ High school degree } & $-0,6402$ & $* * *$ & $-0,6298$ & $* * *$ & $-0,4972$ & $* * *$ & $-0,5441$ & $* * *$ \\
\hline & $(0,0691)$ & & $(0,0438)$ & & $(0,0872)$ & & $(0,0438)$ & \\
\hline & {$[-0,0174]$} & & {$[-0,0153]$} & & {$[-0,007]$} & & {$[-0,006]$} & \\
\hline \multirow[t]{3}{*}{ University degree } & $-0,9897$ & $* * *$ & $-1,1193$ & *** & $-0,8132$ & $* * *$ & $-1,052$ & $* * *$ \\
\hline & $(0,0638)$ & & $(0,0519)$ & & $(0,0651)$ & & $(0,0438)$ & \\
\hline & {$[-0,0226]$} & & {$[-0,0224]$} & & {$[-0,0096]$} & & {$[-0,0096]$} & \\
\hline \multirow[t]{3}{*}{ Male unemp. } & 0,0584 & $* * *$ & $-0,0127$ & & 0,0636 & $* * *$ & $-0,0457$ & $* * *$ \\
\hline & $(0,0137)$ & & $(0,0120)$ & & $(0,0187)$ & & $(0,0152)$ & \\
\hline & {$[0,0016]$} & & {$[-0,0003]$} & & {$[0,0009]$} & & {$[-0,0005]$} & \\
\hline \multirow[t]{3}{*}{$\begin{array}{l}\text { Median adult male } \\
\text { wage }\end{array}$} & $-0,0087$ & & 0,0566 & & 0,0648 & & $-0,0034$ & \\
\hline & $(0,0332)$ & & $(0,0366)$ & & $(0,0406)$ & & $(0,0314)$ & \\
\hline & {$[-0,0002]$} & & {$[0,0014]$} & & {$[0,0009]$} & & {$[-0,00004]$} & \\
\hline Country dummies? & No & & Yes & & No & & Yes & \\
\hline
\end{tabular}

Note: The coefficients are from logit regressions using ECHP data for 14 countries in eight waves (1994 through 2001). Robust standard errors are shown in parenthesis (clustered by country and year). The sample includes all women aged 18 to 35 . The number of observations is 172,437 . Other variables included in the regressions are benefits, age cubed and a time trend. One asterisk indicates that a variable is significant at the $90 \%$ confidence level, two indicate that a variable is significant at the $95 \%$ level, and three indicate significance at the $99 \%$ level. 
Table 6. Coefficients for the Effect of Benefits on Single Motherhood and Headship (ii).

\begin{tabular}{|c|c|c|c|c|}
\hline \multirow{2}{*}{ a) Group ${ }^{*}$ year dummies } & \multicolumn{2}{|c|}{ Single mother } & \multicolumn{2}{|c|}{ Single head } \\
\hline & 0,1227 & $* * *$ & 0,0774 & ** \\
\hline & $(0,0377)$ & & $(0,0390)$ & \\
\hline & {$[0,00326]$} & & {$[0,00092]$} & \\
\hline \multirow[t]{2}{*}{ b) Group*trend } & 0,1057 & $* * *$ & 0,0689 & ** \\
\hline & $\begin{array}{c}(0,0352) \\
{[0,00282]}\end{array}$ & & $\begin{array}{c}(0,0351) \\
{[0,00082]}\end{array}$ & \\
\hline \multirow[t]{3}{*}{ c) Country dummies, group ${ }^{*} y e a r$ dummies } & 0,0267 & & 0,0332 & * \\
\hline & $(0,0208)$ & & $(0,0197)$ & \\
\hline & {$[0,00068]$} & & {$[0,00038]$} & \\
\hline \multirow[t]{2}{*}{ d) Country dummies, group*trend } & 0,0118 & & 0,0224 & \\
\hline & $\begin{array}{l}(0,0194) \\
{[0,0003]}\end{array}$ & & $\begin{array}{l}(0,0178) \\
{[0,00025]}\end{array}$ & \\
\hline \multirow[t]{2}{*}{ e) Country dummies*trend } & $-0,0225$ & & $-0,0026$ & \\
\hline & $\begin{array}{c}(0,0239) \\
{[-0,00057]}\end{array}$ & & $\begin{array}{c}(0,0226) \\
{[-0,00003]}\end{array}$ & \\
\hline
\end{tabular}

Note: The coefficients are from logit regressions using ECHP data for 14 countries in eight waves (1994 through 2001). Robust standard errors are shown in parenthesis (clustered by country and year in all specifications). Marginal effects are in brackets. The sample includes all women aged 18 to 35 . The number of observations is 172,437 . Other variables included in the regressions are age, age squared, age cubed, two education dummies, male unemployment rates and median male wages. Two asterisks indicate that a variable is significant at the $95 \%$ level, and three indicate significance at the $99 \%$ level. Benefits are defined as predicted family-related allowances and social assistance received by a typical single head in a given country and period, and are measured in thousands of euros. The dummies for groups of countries include one for the UK and Ireland, one for Spain, Italy, Greece and Portugal, and one for Finland and Denmark. 
Table 7. Coefficients for the Effect of Benefits on Single Motherhood and Headship, Low Education Sample

\begin{tabular}{|c|c|c|c|c|}
\hline & $\begin{array}{l}\text { Single } \\
\text { mother }\end{array}$ & & Single head & \\
\hline \multirow[t]{3}{*}{ a) Cross-section } & 0,2754 & *** & 0,343 & *** \\
\hline & $(0,0382)$ & & $(0,0437)$ & \\
\hline & {$[0,01081]$} & & {$[0,00576]$} & \\
\hline \multirow[t]{3}{*}{ b) Year trend } & 0,2797 & $* * *$ & 0,3338 & $* * *$ \\
\hline & $(0,0407)$ & & $(0,0455)$ & \\
\hline & {$[0,01098]$} & & {$[0,00560]$} & \\
\hline \multirow[t]{3}{*}{ c) Group dummies, year trend } & 0,0365 & & 0,0143 & \\
\hline & $(0,0602)$ & & $(0,0558)$ & \\
\hline & {$[0,00138]$} & & {$[0,00020]$} & \\
\hline \multirow[t]{3}{*}{ d) Country dummies, year trend } & 0,0347 & & 0,0765 & $* *$ \\
\hline & $(0,0426)$ & & $(0,0374)$ & \\
\hline & {$[0,00123]$} & & {$[0,00101]$} & \\
\hline \multirow[t]{3}{*}{ e) Country dummies, group*trend. } & 0,0462 & & 0,0775 & $* *$ \\
\hline & $(0,0385)$ & & $(0,0340)$ & \\
\hline & {$[0,00164]$} & & {$[0,00102]$} & \\
\hline \multirow[t]{3}{*}{ f) Country dummies*trend. } & $-0,0089$ & & 0,0553 & \\
\hline & $(0,0476)$ & & $(0,0448)$ & \\
\hline & {$[-0,00031]$} & & {$[0,00072]$} & \\
\hline
\end{tabular}

Note: The coefficients are from logit regressions using ECHP data for 14 countries in eight waves (1994 through 2001). Robust standard errors are shown in parenthesis (clustered by country and year in all specifications). Marginal effects are in brackets. The sample includes all women aged 18 to 35 with less than a high school degree. The number of observations is 60,579 . Other variables included in the regressions are age, age squared, age cubed, male unemployment rates and median male wages. Two asterisks indicate that a variable is significant at the $95 \%$ level, and three indicate significance at the $99 \%$ level. Benefits are defined as predicted family-related allowances and social assistance received by a typical single head in a given country and period, and are measured in thousands of euros. The dummies for groups of countries include one for the UK and Ireland, one for Spain, Italy, Greece and Portugal, and one for Finland and Denmark. 
Table 8. Coefficients for the Effect of Benefits on Single Motherhood and Headship, by Marital Status.

\begin{tabular}{|c|c|c|c|c|c|c|c|c|}
\hline & \multicolumn{3}{|c|}{ Never married women } & \multicolumn{5}{|c|}{ Ever married with children } \\
\hline & $\begin{array}{l}\text { Single } \\
\text { mother }\end{array}$ & & $\begin{array}{c}\text { Single } \\
\text { head }\end{array}$ & & $\begin{array}{l}\text { Single } \\
\text { mother }\end{array}$ & & $\begin{array}{l}\text { Single } \\
\text { head }\end{array}$ & \\
\hline a) Year trend & $\begin{array}{c}0,1737 \\
(0,0343) \\
{[0,00439]}\end{array}$ & $* * *$ & $\begin{array}{c}0,167 \\
(0,0351) \\
{[0,00156]}\end{array}$ & $* * *$ & $\begin{array}{c}0,1723 \\
(0,0359) \\
{[0,00774]}\end{array}$ & *** & $\begin{array}{c}0,203 \\
(0,0427) \\
{[0,00642]}\end{array}$ & *** \\
\hline $\begin{array}{l}\text { b) Group dummies, } \\
\text { year trend }\end{array}$ & $\begin{array}{c}0,0862 \\
(0,0280) \\
{[0,00198]}\end{array}$ & $* * *$ & $\begin{array}{c}0,0375 \\
(0,0266) \\
{[0,00023]}\end{array}$ & & $\begin{array}{c}0,1139 \\
(0,0364) \\
{[0,00498]}\end{array}$ & *** & $\begin{array}{c}0,078 \\
(0,0305) \\
{[0,00228]}\end{array}$ & ** \\
\hline $\begin{array}{l}\text { c) Country dummies, } \\
\text { year trend }\end{array}$ & $\begin{array}{c}0,0099 \\
(0,0120) \\
{[0,00018]}\end{array}$ & & $\begin{array}{c}0,0016 \\
(0,0153) \\
{[0,00001]}\end{array}$ & & $\begin{array}{c}0,0384 \\
(0,0388) \\
{[0,00161]}\end{array}$ & & $\begin{array}{c}0,0729 \\
(0,0255) \\
{[0,00207]}\end{array}$ & $* * *$ \\
\hline d) Group*trend & $\begin{array}{c}0,0896 \\
(0,0281) \\
{[0,00205]}\end{array}$ & $* * *$ & $\begin{array}{c}0,0424 \\
(0,0269) \\
{[0,00026]}\end{array}$ & & $\begin{array}{c}0,1271 \\
(0,0413) \\
{[0,00555]}\end{array}$ & $* * *$ & $\begin{array}{c}0,0868 \\
(0,0363) \\
{[0,0025]}\end{array}$ & ** \\
\hline $\begin{array}{l}\text { e) Country dummies, } \\
\text { group*trend. }\end{array}$ & $\begin{array}{c}0,0008 \\
(0,0111) \\
{[0,00001]}\end{array}$ & & $\begin{array}{c}-0,0069 \\
(0,0132) \\
{[-0,00004]}\end{array}$ & & $\begin{array}{c}0,0437 \\
(0,0455) \\
{[0,00183]}\end{array}$ & & $\begin{array}{c}0,0756 \\
(0,0285) \\
{[0,00214]}\end{array}$ & $* * *$ \\
\hline $\begin{array}{l}\text { f) Country } \\
\text { dummies*trend. }\end{array}$ & $\begin{array}{c}-0,0059 \\
(0,0121) \\
{[0,00011]}\end{array}$ & & $\begin{array}{c}-0,0136 \\
(0,0159) \\
{[-0,00007]}\end{array}$ & & $\begin{array}{c}-0,0672 \\
(0,0654) \\
{[-0,00266]}\end{array}$ & & $\begin{array}{c}0,0035 \\
(0,0318) \\
{[0,00010]}\end{array}$ & \\
\hline
\end{tabular}

Note: The coefficients are from logit regressions using ECHP data for 14 countries in eight waves (1994 through 2001). Robust standard errors are shown in parenthesis (clustered by country in all specifications but $b$, where they are clustered by groups of countries). Marginal effects are in brackets. The sample includes all women aged 18 to 35 . The number of observations is 91,871 in the never married regressions, and 60,565 in the ever married regressions. Other variables included in the regressions are age, age squared, age cubed, two education dummies, male unemployment rates and median male wages. One asterisk indicates that a variable is significant at the $90 \%$ confidence level, two indicate that a variable is significant at the $95 \%$ level, and three indicate significance at the $99 \%$ level. Benefits are defined as median family-related allowances and social assistance received by single heads in a given country and period (never married heads in the regressions for never married women, and ever married heads in the regressions for ever married women with children). The dummies for groups of countries include one for the UK and Ireland, one for Spain, Italy, Greece and Portugal, and one for Finland and Denmark. 
Table 9. Coefficients for the Effect of Benefits on Single Motherhood and Headship, Specifications with Individual Fixed Effects.

\begin{tabular}{lcccc}
\hline & \multicolumn{2}{c}{ Age cut 35 } & \multicolumn{2}{c}{ Age cut 45 } \\
\hline & Single mother & Single head & Single mother & Single head \\
\hline a) Baseline & 0,033 & $-0,0017$ & 0,0236 & $-0,0014$ \\
& $(0,0421)$ & $(0,0497)$ & $(0,0299)$ & $(0,0332)$ \\
b) Year trend & 0,0335 & $-0,0014$ & 0,0236 & $-0,0015$ \\
& $(0,0421)$ & $(0,0497)$ & $(0,0300)$ & $(0,0332)$ \\
c) Year dummies & 0,0441 & 0,0147 & 0,0516 & $*$ \\
& $(0,0445)$ & $(0,0537)$ & $(0,0314)$ & $(0,017$ \\
d) Group*trend & 0,0349 & 0,0093 & 0,0251 & 0,0079 \\
& $(0,0422)$ & $(0,0494)$ & $(0,0301)$ & $(0,0332)$ \\
e) Group*year dummies & 0,045 & $-0,0052$ & 0,0669 & $*$ \\
& $(0,0489)$ & $(0,0591)$ & $(0,0342)$ & $(0,0386$ \\
& & & & \\
f) Country*trend & $-0,014$ & 0,0493 & $-0,0565$ & 0,0121 \\
& $(0,0539)$ & $(0,0620)$ & $(0,0394)$ & $(0,0434)$ \\
& & & & \\
\hline
\end{tabular}

Note: The coefficients are from fixed effects logit regressions using ECHP data for 14 countries in eight waves (1994 through 2001). Standard errors are shown in parenthesis. The sample includes all women aged 18 to 35 (18 to 45 in columns 3 and 4). The number of observations is 8,755 (17,632 for 18-45 age cut) in the single mothers regressions and 6,476 (14,260 for 18-45 age cut) in the single heads regressions. Other variables included in the regressions are age, age squared, age cubed, education dummies, male unemployment, and male wage. One asterisk indicates that the variable is significant at the $95 \%$ confidence level, two indicate significance at the $99 \%$ confidence level. Benefits are defined as median family-related allowances and social assistance received by single heads in a given country and period. 
Appendix. Predicted Benefits for Two Parent Families, 1994 and 2001.

\begin{tabular}{|l|c|c|}
\hline & $\mathbf{1 9 9 4}$ & $\mathbf{2 0 0 1}$ \\
\hline Austria & 2866 & 3571 \\
\hline Belgium & 2561 & 3115 \\
\hline Denmark & 3329 & 4195 \\
\hline Finland & 3663 & 4162 \\
\hline France & 1379 & 1640 \\
\hline Germany & 1198 & 3147 \\
\hline Greece & 27 & 41 \\
\hline Ireland & 497 & 975 \\
\hline Italy & 123 & 115 \\
\hline Luxembourg & 3346 & 5215 \\
\hline Netherlands & 1452 & 1546 \\
\hline Portugal & 234 & 428 \\
\hline Spain & 52 & 82 \\
\hline United Kingdom & 1099 & 2149 \\
\hline
\end{tabular}

Note: ECHP data (excluding Sweden). Predicted values from benefit regressions are the country level with explanatory variables number of children, hours worked by the mother, and year. Waves 1 through 8, except for Finland (waves 3 through 8) and Austria (waves 2 through 8). Two parent families are defined as households headed by a couple with children under 18 present. Benefit levels are expressed in euros and include family-related allowances and social assistance (ECHP variables H133 and H137). Predicted benefits are calculated for the sample of two parent families where the mother is 18 to 54 years old. 